\title{
Nanoindentation Analysis of Inconel 625 Alloy Weld Overlay on 16Mo3 Steel
}

Patrik Klučiar, Igor Barenyi (0000-0002-9296-600X), Jozef Majerík (0000-0002-6577-1987)

Faculty of Special Technology, Alexander Dubček University of Trenčín, Ku Kyselke 469, 911 06, Trenčín, Slovakia.Email: patrik.kluciar@tnuni.sk, igor.barenyi@tnuni.sk, jozef.majerik@tnuni.sk

This article deals with nanoindentation analysis of welded overlay layer of Inconel 625 alloy on $16 \mathrm{Mo3}$ steel and their interface (transition zone). The microstructure of weld metal is analyzed, as well as the weld-on steel and subsequently nanoindentation properties (nanohardnes, reduced modulus of elasticity) of selected structural components. The weld of Inconel 625 alloy is realized on a tube made of $16 \mathrm{Mo3}$ steel, which is bent by the so-called critical bending $(d \leq 0,7 \mathrm{D})$. The article also deals with the change of investigated properties of the weld after that bending. The samples prepared from the areas with highest compressive and tensile load after the tube bending on outer, respectively inner bend arc were used for the research. Nanoindentation analysis was performed with using a Hysitron Triboindenter TI950 and its evaluation software Triboscan.

Keywords: nanoindentation, weld overlay, Inconel 625 alloy, 16Mo3 steel, microstructure

\section{Introduction}

Process of fatigue under various conditions as are high temperature load or pressure is main theme of nowadays construction materials. Common construction steels could be handle the temperature 500 ${ }^{\circ} \mathrm{C}$ but without loading by the pressure. Because in incinerators, steam boilers and etc. occurs except raising temperature, raising pressure or chemical reactions too, is necessary used heat-resistant steel as $16 \mathrm{Mo} 3$ is. This steel, also referred as 1.5415 with standard EN10028, is specific heat-resistant low-alloyed chromium-molybdenum steel usable in work environment with higher working temperature. Thanks to content of chromium and molybdenum, this steel has excellent heat and corrosion resistance, better creep resistance and higher strength even at warmed on higher work temperatures. Maximum temperature of use is $530^{\circ} \mathrm{C}$. Thanks to this, this steelisused as welding steel in production of industrial boilers, pressure vessel on oil, gas and for chemical industry. $16 \mathrm{Mo} 3$ is widely used construction material, especially in energy industry. $[1,2,3,4,5]$.

Heat resistance of steel can be increased by weld overlay of heat-resitant alloys as is Inconel 625. Inconel is nickel based alloy ( $\mathrm{NiCrMo}$ ) used not only for heat-resistance, but thank to its corrosion resistance properties too. $[6,7,8]$. Inconel have usage in aviation, chemical, ship, nuclear industries, combustion turbines, petroleum and natural gas mining. $[6,7,8,9,10]$. Cold Metal transfer (CMT) is one of possible and mostly used method to create the weld overlay with specific properties. Also, properties of the Inconel layer or the interface between layer and base materials (Fig. 1) is a focus of many research articles
$[1,11,12,13]$.

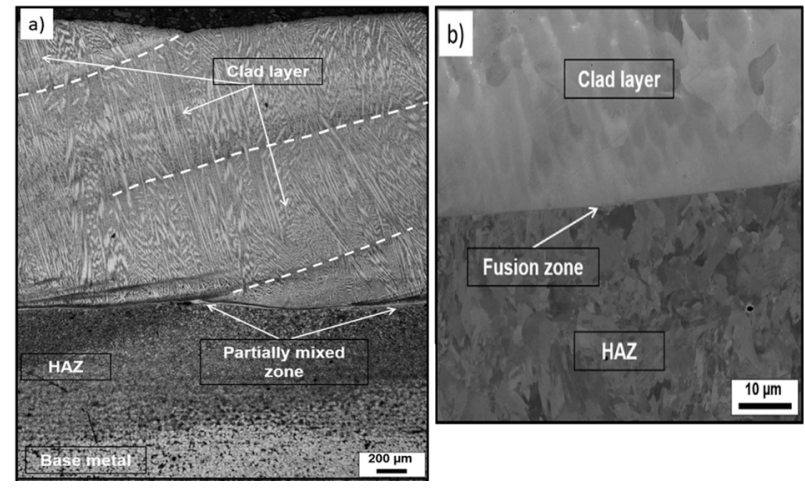

Fig. 116Mo3 layer covered by layer of Inconel 625obtained by CMT technology: a) overwiev ( $L M$ picture), b) fusion zone at higher magnification [16]

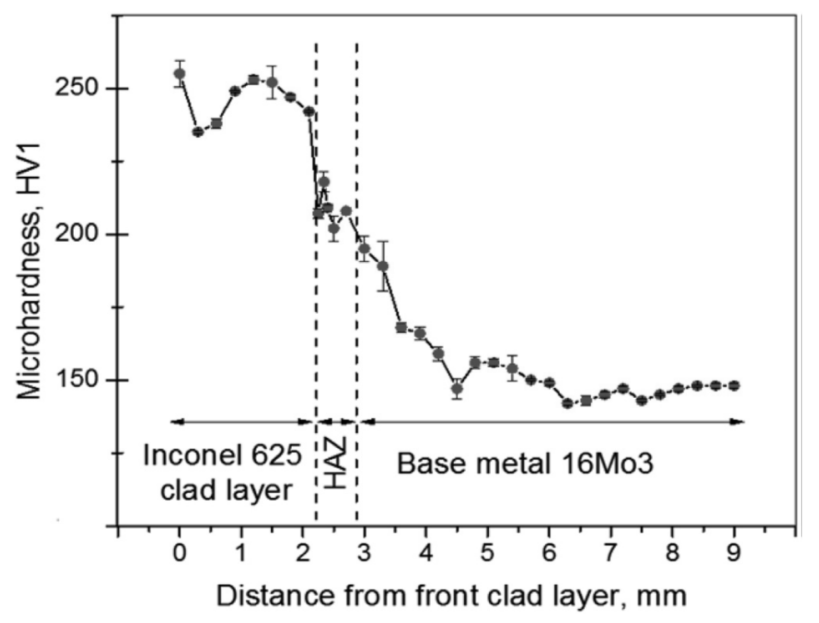

Fig. 2 Distribution of the microhardness profile in the direction perpendicular to the heat affected zone (HAZ) and to the base material [16] 
These work mainly studied the course of microhardness from the layer through the interface (Inconel - Steel) to the base material (Steel) as is shown in Fig. 2. The microhardness of the clad layer was higher than in the heat affected zone and the base metal. The average microhardness of the clad layer was $250 \pm 10$ HV1 and $205 \pm 8$ HV1, respectively. The microhardness of the CMT-coated layer is similar to those obtained for the Inconel 625 laser-coated surface $[14,15]$. The average hardness of $16 \mathrm{Mo} 3$ steel is equal to 150 \pm 15 HV1.

The microstructure of weld overlay layer of Inconel 625 also has been studied $[15,16]$ and consists of dendritic structure where the dendrites are the $\gamma$ phase (Fig. 3). The authors confirmed through the research that it is possible to assess the mechanical properties of hard particles surrounded by a soft matrix if the plastic zone remains smaller than the offset phase. If, during the nanoindentation of the hard particles, the plastic deformation spreads to the surrounding soft phase, the hard particle is immersed in a softer matrix. The dendritic region of the $\gamma$ phase (matrix) had an average hardness of $392 \mathrm{HV}$, which is much lower than the hardness of the secondary phases (493 HV). The indentation depth was $433 \pm 22 \mathrm{~nm}$ [17].
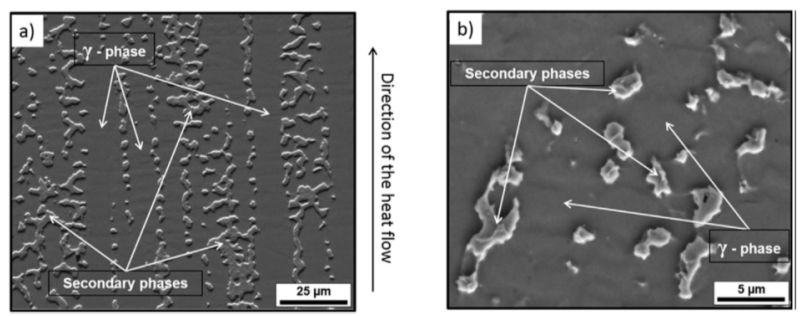

Fig. 3 Microstructure (SEM eSE) layer covered by Inconel 625 layer showing a dendritict structure secondary phases create along a dendritic areas [15]

In our case, the Inconel layer is additionally bent by the so-called critical bending $(\mathrm{d} \leq 0,7 \mathrm{D})$. The bending process influences the material by additional inner stresses. On the outside of the bend, in accordance with the theoretical principles of bending, a tensile load occurs and the wall thickness is $80-90 \%$ lower than the standard one. In contrast, the inner side of the arc is subjected to pressure and wall thickness of the pipe increases. This processing of the overlayed material also influences properties of the layer as well as interface between layer and base material.

\section{Material and methods}

\section{$2.116 \mathrm{Mo} 3$ steel}

Steel $16 \mathrm{Mo} 3$ is middle alloyed heat resistance steel for using at higher temperatures and pressures. It is good for heat and cold forming, corrosion resistance in water steam environment at $530^{\circ} \mathrm{C}$. It is usable for energetic and chemical devices. It is delivered in the state after annealing, where the resulting structure is ferrite and perlite. Microstructure of basic material (steel 16Mo3) used for experiment is in Fig. 4. Ferrite grains wihth perlite predominantly formed atthegrains borders are observed in the structure. On the boundaries or near them is possibly to observe finely precipitated carbides.

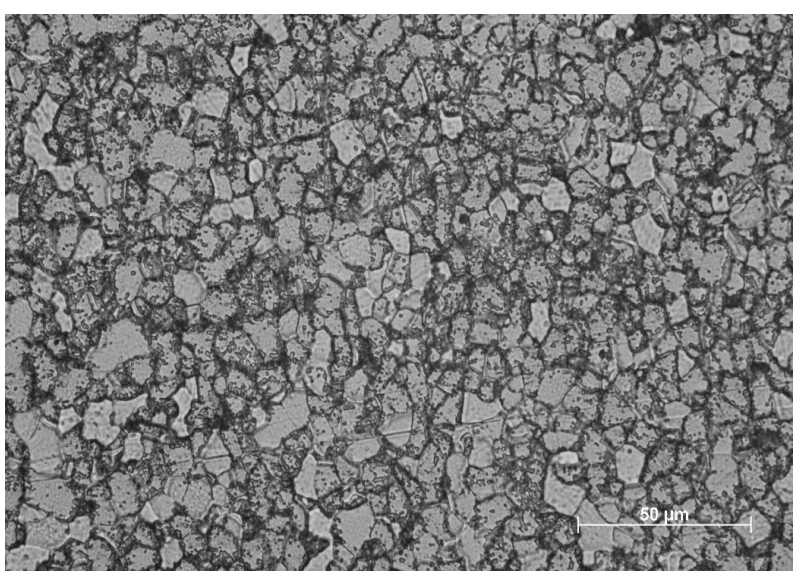

Fig. 4 Microstructure of $16 \mathrm{Mo3}$ steel

Selection criterion for this steel is strength, hardness and toughness. At the room temperature, tension under yield strength, don't make a permanent damage, but at higher temperatures is this situation different. At the temperature over $350{ }^{\circ} \mathrm{C}$, hardness and yield strength decrease, also occurs creep, what can be cause break a machine after a short time for common construction steel. $16 \mathrm{Mo} 3$ steel has good mechanical properties also at higher temperature. Thanks to alloying element, which is molybdenum, has steel $16 \mathrm{Mo} 3$ better heat resistance. Molybdenum is connecting with carbon and makes carbide, which are increase wear and tempering resistance. Basic chemical composition and mechanical properties are shown in Tab. 1.

Tab. 1 Basic chemical composition and mechanical properties of $16 \mathrm{Mo} 3$ steel

\begin{tabular}{|c|c|c|c|c|c|c|c|c|}
\hline Material & wt. $\%$ & $\mathrm{C}$ & $\mathrm{Mn}$ & $\mathrm{Si}$ & $\mathrm{Al}$ & $\mathrm{P}$ & $\mathrm{S}$ & $\mathrm{Fe}$ \\
\hline \multirow{4}{*}{$\begin{array}{c}\text { Steel } \\
16 \mathrm{Mo3}\end{array}$} & min. & 0.1 & 0.5 & 0.15 & -- & -- & -- & \multirow{2}{*}{ Bal. } \\
\hline & $\max$. & 0.20 & 0.8 & 0.37 & 0.015 & 0.04 & 0.04 & \\
\hline & \multicolumn{2}{|c|}{$\begin{array}{c}\text { Tensile strength } \\
\text { Rm }[\mathrm{MPa}]\end{array}$} & \multicolumn{2}{|c|}{ Yield $\mathrm{R}_{\mathrm{p} 0,2}[\mathrm{MPa}]$} & \multicolumn{2}{|c|}{ Ductility A [\%] } & \multicolumn{2}{|c|}{ Hardness HV } \\
\hline & \multicolumn{2}{|c|}{440} & \multicolumn{2}{|c|}{380} & \multicolumn{2}{|c|}{30} & \multicolumn{2}{|c|}{150} \\
\hline
\end{tabular}




\subsection{Inconel 625 alloy}

Inconel 625 is heat-resistant and creep resistant nickel alloy (NiCr22Mo9Nb) alloyed with $\mathrm{Cr}, \mathrm{Mo}, \mathrm{Nb}$, Fe and other elements. The alloy is designed to be reinforced with a substitute solid Ni solution, but due to the presence of $\mathrm{Nb}$ and other elements, precipitation strengthening may also be present. Ternary diagram of $\mathrm{Ni}-\mathrm{Cr}-\mathrm{Mo}$ sysem with position of the Inconel 625 alloy according to fractionsof the main alloying elements is in Fig. 5. The diagram shows homogeneous austenitic structure for the alloy.

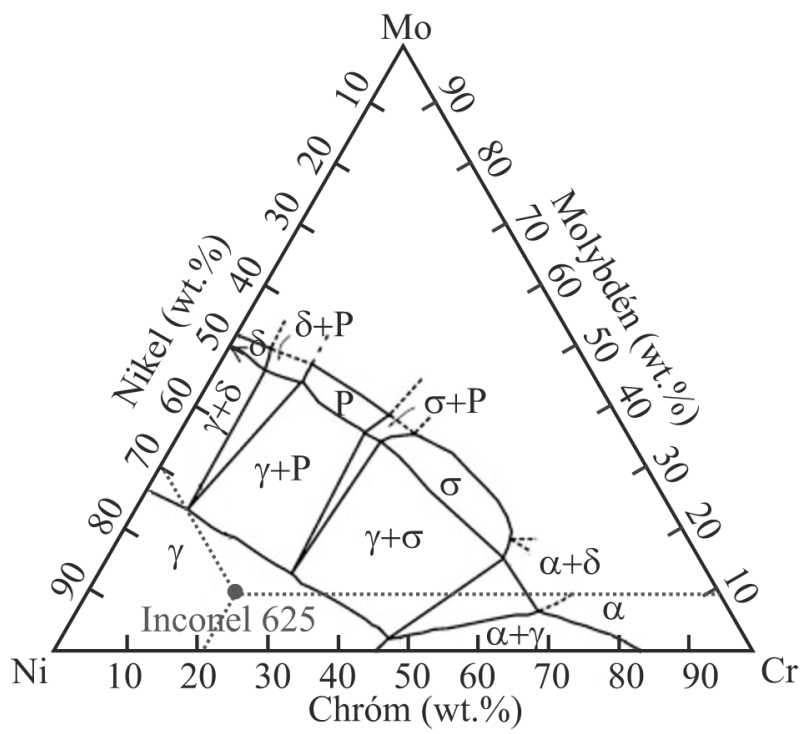

Fig. 5 Ternary diagram of NiCrMo with Inconel 625 alloy positon
Inconel 625 is an alloy of nickel, chromium and molybdenum (tab. 2), with addition of niobium, which is connecting with molybdenum and that strengthens the metal matrix, thank to which it is ensured high strength without necessary next heat treatment. Due to the presence of niobium in the Inconel 625 alloy, precipitation hardening occurs by forming $\mathrm{Ni}_{3} \mathrm{Nb}$ phase on the temperature $537{ }^{\circ} \mathrm{C}$.Inconel 625 alloy have high, creep resistance, fatigue strength, heat-fatigue strength, high pitting and crevice corrosion resistance and high temperature oxidation resistance too. Operating temperature of Inconel is from cryogenic temperatures up to $980{ }^{\circ} \mathrm{C}$. Inconel 625 is well thermoforming, but heating temperature should be somewhere around $1176{ }^{\circ} \mathrm{C}$, but not higher. Basic microstructure of Inconel 625 in as-delivwered state is homogenous microstrucrure consists of $\gamma$ phase grains (Fig. 6).

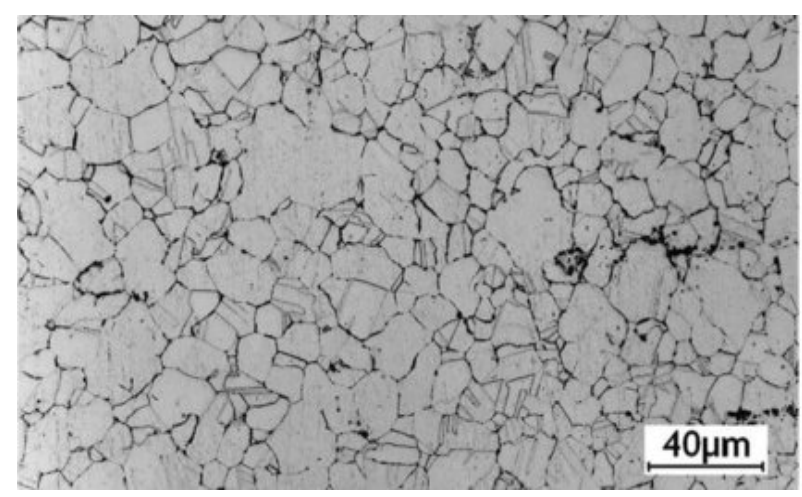

Fig. 6 Microstructure of Inconel 625 alloy

Tab. 2 Basic chemical composition and mechanical properties of Inconel 625alloy used for experiment

\begin{tabular}{|c|c|c|c|c|c|c|c|c|c|c|c|c|c|c|}
\hline Material & wt. $\%$ & $\mathrm{Cr}$ & Mo & $\mathrm{Co}$ & $\mathrm{Nb}$ & $\mathrm{Ti}$ & $\mathrm{Fe}$ & $\mathrm{C}$ & $\mathrm{Mn}$ & $\mathrm{Si}$ & $\mathrm{Al}$ & $\mathrm{P}$ & S & $\mathrm{Ni}$ \\
\hline \multirow{4}{*}{$\begin{array}{c}\text { Inconel } 625 \\
(\mathrm{NiCr} 22 \mathrm{Mo} 9 \mathrm{Nb})\end{array}$} & $\min$. & 20 & 8 & -- & 3,15 & -- & -- & -- & -- & -- & -- & -- & -- & \multirow{2}{*}{ Bal. } \\
\hline & $\max$ & 23 & 10 & 1 & 4.15 & 0.4 & 5 & 0.1 & 0.5 & 0.5 & 0.4 & 0.015 & 0.015 & \\
\hline & \multicolumn{4}{|c|}{$\begin{array}{c}\text { Tensile strength } \\
\text { Rm [MPa] }\end{array}$} & \multicolumn{4}{|c|}{ Yield $\mathrm{R}_{\mathrm{p} 0,2}[\mathrm{MPa}]$} & \multicolumn{3}{|c|}{$\begin{array}{l}\text { Elongation(at } \\
\left.20^{\circ} \mathrm{C}\right) \mathrm{A}[\%]\end{array}$} & \multicolumn{3}{|c|}{$\begin{array}{c}\text { Hardness HV5 } \\
\text { (before cold rolling) }\end{array}$} \\
\hline & \multicolumn{4}{|c|}{965} & \multicolumn{4}{|c|}{490} & \multicolumn{3}{|c|}{50} & \multicolumn{3}{|c|}{200} \\
\hline
\end{tabular}

\subsection{Experimental material processing}

Semi-finished product - bimetallic tube of $16 \mathrm{Mo} 3$ steel (outer $\mathrm{d}=\varnothing 38 \mathrm{~mm}$ ) with overlay weld of Inconel 625 alloy (Fig. 7)was usedfor experiment. Wall thickness of tube is $7 \mathrm{~mm}$, where the average thickness of weld layer is $3,5 \mathrm{~mm}$.

The weld overlay was realized with using of the CMT method [14]. A nickel refractory alloy wire with a diameter of $1 \mathrm{~mm}$ was used for welding. After the CMT process, a $180^{\circ}$ bend was created on the tube with extended ends (Fig. 8). It is a critical bend, where $\mathrm{d} \leq 0,7 \mathrm{D}$. The experimental samples were prepared from the location in the top of outer bending arc $(\mathrm{OBA})$ with the highest inner tensile stresses and from the bottom of outer bending arc (IBA).

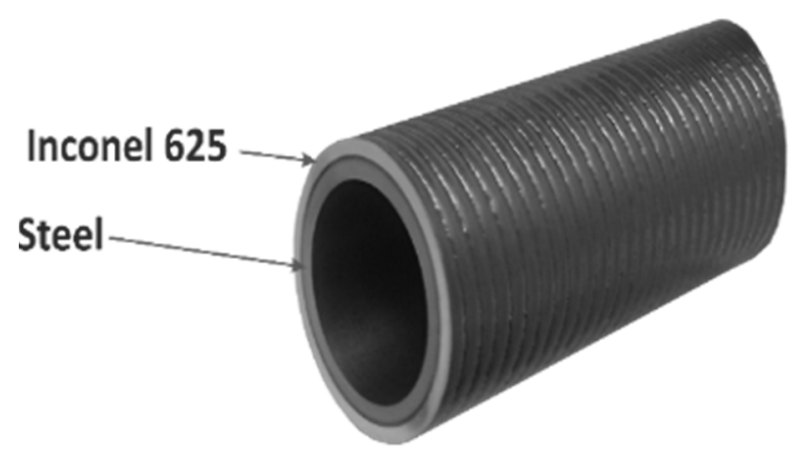

Fig. 7 Basic semi-finished product used for experiment sample 


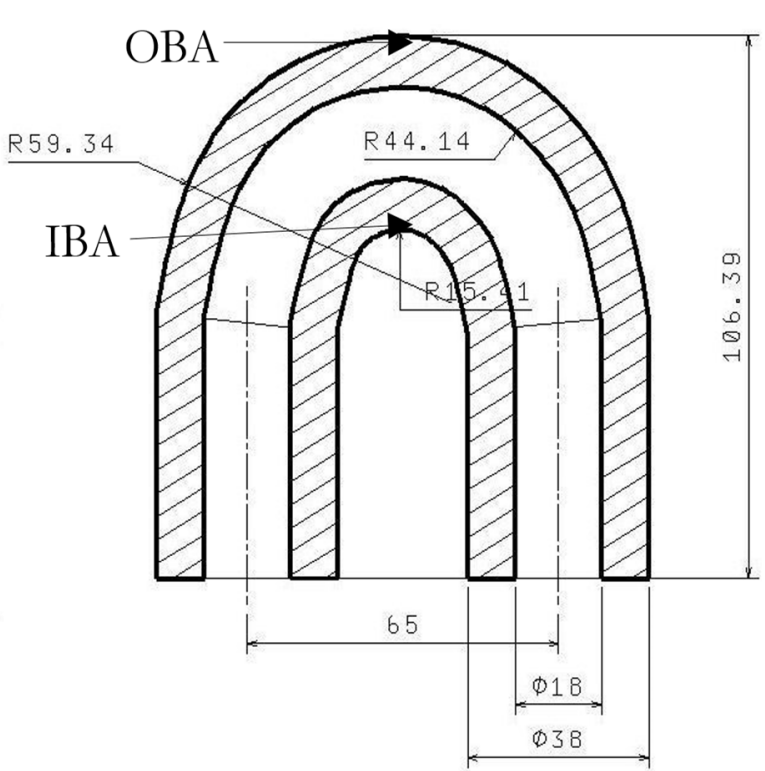

Fig. $\boldsymbol{8}$ Bending of experimental tube with places selected for sample preparation

\subsection{Quasi-static nanoindentation}

Quasi-static nanoindentation is defined as simple deformation test, in which the extent of tip penetration into the material is evaluatedin nanometers. In most nanoindentation tests, indirect measure of contact areais performed, what means contact area between indentation tip and test sample. In common indentation tests is contact area calculated from direct dimensional measurement of created impression in the surface of test sample after load removal. In nanoindentation is size of created imprint is of the order of few nanometers and it is too small for direct measure. Therefore, it is common to determine the area of contact by measuring the depth of penetration of the indenter into sample surface. Thanks to this and know geometry of indentor is possible to evaluate the contact area with indirect method in full load.

Objective of nanoindentation tests is to determine local hardness of material and his modulus of elasticity in a measuring point. Value of nanohardness represents the average pressure of tip with material surface, and it is obtained by the ratio of the applied load and the projection area of the contact. During the nanoindentation test it is measure a movement of indenter under the influence of load and contact area size, which is determine indirectly from penetration depth from know indenter geometry. At the same time, course of loading and penetration depth to test subject surfaceis recordedduring indentation. Graphic interpretation of that relation is nanoindentation (load-displacement) curve (Fig. 9).

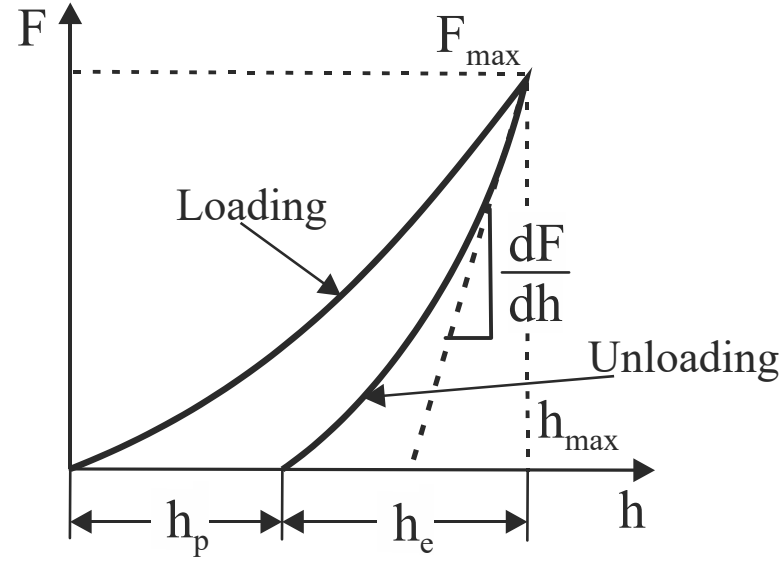

Fig. 9 Nanoindentation curve of real material

Where:

F...Applied load,

$F_{\max }$...Max. load,

h...Deformation (depth),

$h_{\mathrm{p}}$...Plastic part of deformation,

$h_{\mathrm{e}}$...Elastic part of deformation,

$\mathrm{h}_{\max }$...Max. deformation.

Nanohardness $\mathrm{H}$ can be determined from elasticplastic part of curve and imprint parameters by equation (1).

$$
\boldsymbol{H}=\frac{\boldsymbol{F}}{\boldsymbol{A}_{\boldsymbol{c}}}
$$

Where $F$ is the load and $A_{c}$ is the projection contact area, determined for the indentation depth $h$. Reduced modulus of elasticity $E_{r}$ is determined from slope of the elastic part of the curve $(S)$ by equation (2).

$$
S=\frac{d F}{d h}=\frac{2 E_{r} \sqrt{A_{c}}}{\sqrt{\pi}}
$$

Resulting deformation at nanoindentation is given by a combination of material properties of indenter and experimental material.Reduced modulus of elasticity $E_{r}$ therefore includes influence of both of these parameters and it is defined by equation (3).

$$
\frac{1}{E_{r}}=\frac{1-v_{s}^{2}}{E_{S}}+\frac{1-v_{i}^{2}}{E_{i}}
$$

Where $E_{s}, v_{s}$ are Young's modulus of elasticity and Poisson number of experimental material, $E_{i}, v_{i}$ are Young's modulus of elasticity and Poisson number of indenter. Equation [3] can be used to calculate the standard Young's modulus $\left(E_{s}\right)$ from the reduced modulus $\left(E_{r}\right)$, if allmentioned material characteristics are known. Indenter properties are mostly precisely set by producer. When using a diamond indenter, which behaves very rigidly $\left(E_{i} \approx 1200 \mathrm{GPa}\right)$, it is possibleto omit the component related tothe properties of the indenterfrom equation (3) and simplify it so to the equation (4).

$$
\frac{1}{E_{r}}=\frac{1-v_{s}^{2}}{E_{S}}
$$


Quasistatic nanoindentation analysis within presented experiment was performed using a Hysitron Triboindenter TI 950 and its Triboscan evaluation software. As a first step, a SPM (Scanning probe microscopy) scan of the area was performed at a selected location of the microstructure. The system has buil-in one objective optical microscope what helps to find needed measure location on the sample surface. Standard trapezoid with a maximum load $F=5000$ $\mu \mathrm{N}$ and identation time $t=2 \mathrm{~s}$ was used as the loading curve. SPM scan area 50x50 $\mu \mathrm{m}$ was choosen for the general can. For more detailed scan, load $F=1000 \mu \mathrm{N}$ and $2 \times 2 \mu \mathrm{m}$ area were chosen. A nanoindentation curve was recorded at each evaluation point, followed by evaluation of the nanohardness $H$ and the reduced modulus of elasticity.

In next experiment, total inner and outer bending wall thickness of pipeswas also evaluated, thickness of Inconel 625 layer on inner and outer bending side in bending cut of pipe.The cut was led by geometrical center of pipe. These thicknesses were well visually observable from this cut, they were evaluated using a magnifying glass, a caliper and micrometer.

\section{Result and discussion}

SPM scan of Inconel 625 weld area with dimension $50 \times 50 \mu \mathrm{m}$ is in Fig. 10. The area is located in the top of outer bending arc with maximal tensile stresses (OBA). The grains of $\gamma$ are stretched in the direction of the applied tension during bending process. The nanoindentation points were chosen in order to cover all main present structure components and are highlighted in the figures. Resulting values obtained by quasistatics analysis are listed in Tab. 3. Gently scattered particles of precipitatesare also visible in the scan, which have been the subject of futher quasi-static nanoindentation with higher resolution. Detailed view of precipitate is in $2 \times 2 \mu \mathrm{m}$ SPM scan in Fig. 11. Resulting values obtained by its analysis are listed in tab. 4 .

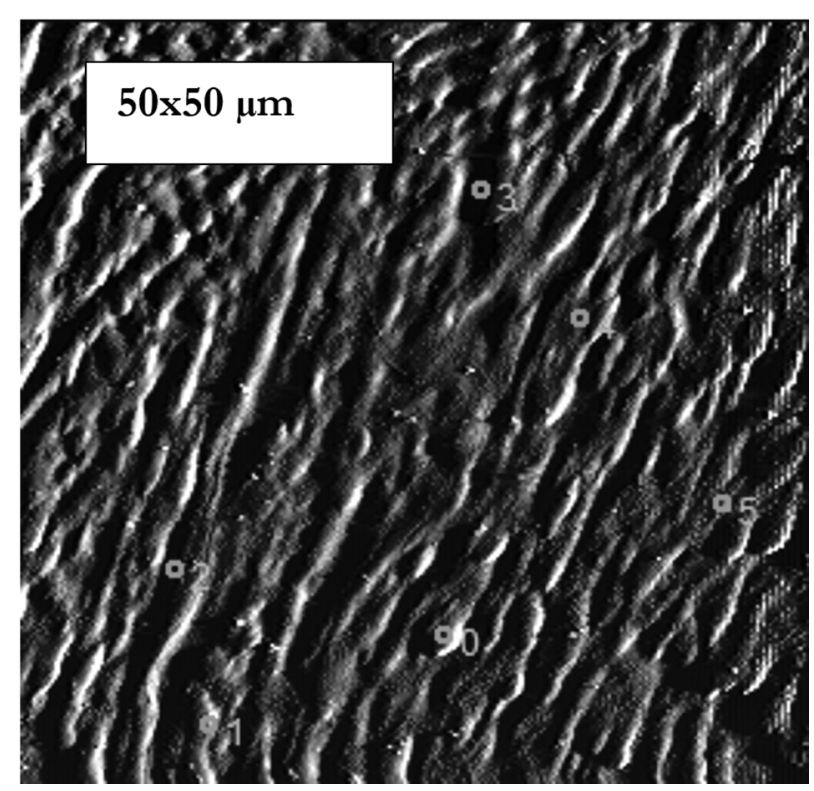

Fig. 10 SPM scan of overaly weld area $(50 \times 50 \mu \mathrm{m})$

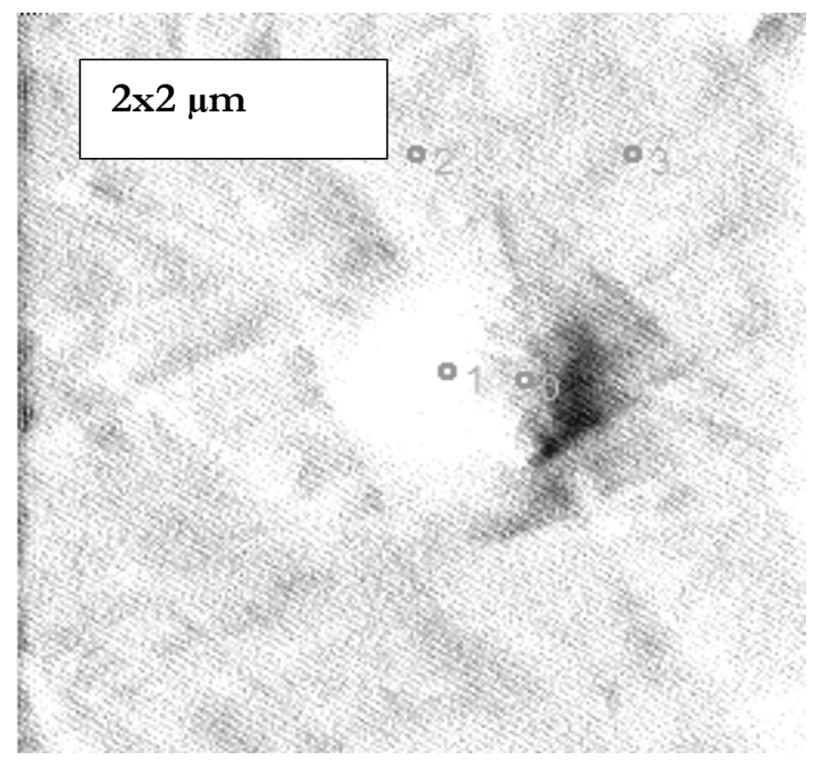

Fig. 11 Detail of precipitate in Inconel 625 deposit $(2 \times 2 \mu \mathrm{m})$

Tab. 3 Resulting values of quasi-static analysis - SPM scan $50 \times 50 \mu \mathrm{m}$

\begin{tabular}{|c|c|c|c|c|c|c|c|}
\hline Point no. & 0 & 1 & 2 & 3 & 4 & 5 & Average \\
\hline$H[\mathrm{GPa}]$ & 6.85 & 7.58 & 7.10 & 7.66 & 7.78 & 7.80 & $7.58 \pm 0.25$ \\
\hline$E_{r}[\mathrm{GPa}]$ & 183.34 & 180.08 & 195.80 & 209.50 & 184.01 & 205.83 & $193.09 \pm 11.4$ \\
\hline
\end{tabular}

Tab. 4 Resulting values of quasi-static analysis - SPM scan $2 \times 2 \mu m$

\begin{tabular}{|c|c|c|c|c|c|c|}
\hline Point no. & 0 & 1 & 2 & 3 & $\begin{array}{c}\text { Average } \\
\text { points 0-1) } \\
\text { precipitate }\end{array}$ & $\begin{array}{c}\text { Average } \\
\text { (points 2-3) } \\
\text { matrix }\end{array}$ \\
\hline$H[\mathrm{GPa}]$ & 12.20 & 13.70 & 8.65 & 8.16 & $12.95 \pm 0.75$ & $8.40 \pm 0.24$ \\
\hline$E_{r}[\mathrm{GPa}]$ & 242.35 & 237.92 & 208.29 & 208.69 & $240.14 \pm 2.21$ & $208.49 \pm 0.2$ \\
\hline
\end{tabular}


Since the weld structure is homogeneous and formed by a solid solution $\gamma$, the values of nanohardness $H$ and reduced modulus of elasticity $E_{r}$ have approximately the same value in each of the evaluated positions 0 to 5 . Minor differences may be due to uneven grain distribution, some places are located in dendritic grain arms and others are close to grain boundaries. In the case of the second nanoindentation analysis, focused on the precipitate, significantly higher values of nanohardness $H$ and reduced modulus of elasticity $E_{r}$ were mearusred. This confirms the assumption that the particle is the precipitate with different material properties than the matrix.Values of $H$ and $E_{\mathrm{r}}$ for the matrix are very comparable with first nanoindentation measurement in the $50 \times 50 \mu \mathrm{m}$ area.

Also nanoindentation course through interface between Inconel 625 ans $16 \mathrm{Mo} 3$ steel was measured in order to map the transition zone between layer and basic material. The series of nanoindentation measurements were realized through the interface in two areas where the distance between indentation place is constant $(20 \mu \mathrm{m})$. Measured points are fitted with using of polynomial regression. Final results are shown in Fig. 12. The Curve with dotted line represents area close to the outer arc of the bend (OBA), where the solid curve represents the area close to the inner arc of the bend (IBA). Tensile stresses caused by the bending dominate in $\mathrm{OBA}$ area and pressure inner stresses in the IBA area. This also also correspond with the results from nanohardness courses. Transition zone determined from the Fig. 12 is narrower in case of the OBA (about $50 \mu \mathrm{m}$ ) than in IBA area (about $70 \mu \mathrm{m}$ ). Measurement of nanohardness in the IBA area showed higher values than nanohardnesses in $\mathrm{OBA}$ area. Applied inner compressive stresses in IBA causes strengthening acting against the nanoindentation tip in the indetation process.

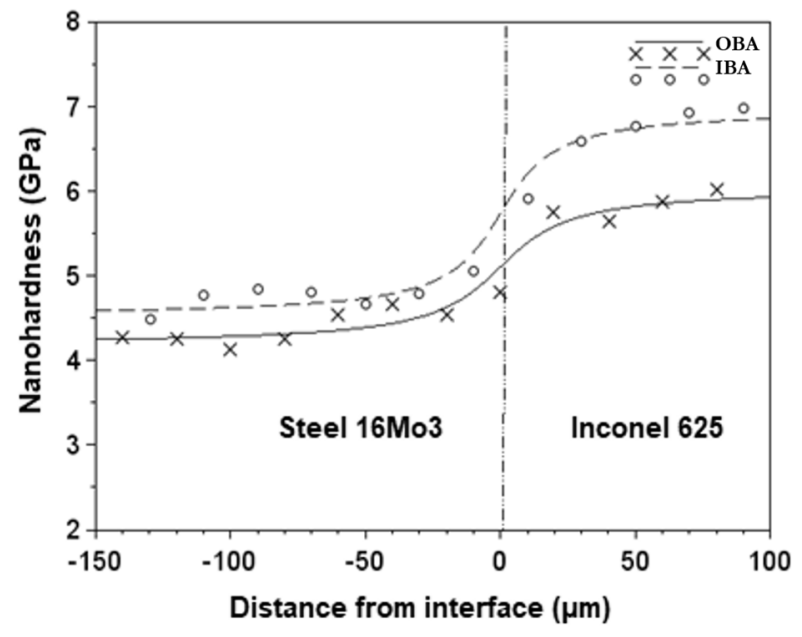

Fig. 12 Comparison of obtained nanohardness curves at the outer $(O B A)$ and inner $(I B A)$ bending arc

\section{Conclusion}

The subject of the research was the welding overlay of the Inconel 625 alloy on the base material - steel 16Mo3. A semi-finished product was used for the research - a welded pipe (Ø38 mm), on which a critical bend of $180^{\circ}$ was created. The nanoindentation analysis of the weld metal microstructure was performed after its analysis by SPM scanning. Next step was the course of nanohardness through the interface steel $16 \mathrm{Mo} 3$ - Inconel 625 measurement. The following conclusions follow from the performed experiments:

- The structure of the deposit is homogeneous formed by a solid solution $\gamma$. The grains are deformed in some places due to bending stresses. Average measured values of nanogardnes and reduced elastic modulus for $\gamma$ grain are $H=7.85 \pm 0.25 \mathrm{GPa}$ and $E_{\mathrm{r}}=$ $193.09 \pm 11.4 \mathrm{GPa}$.

- Irregurally distributed precipitates was observed in $\gamma$ grains within SPM scan. Nanoindentation of the precipitate were measured as $H=12.95 \pm 07.25 \mathrm{GPa}$ and $E_{\mathrm{r}}=$ $240.14 \pm 2.21 \mathrm{GPa}$.

- Results of the nanoindentation analysis are in accordance with conlusion of investigations of other author which examined similar materials.

- Nanohardness curves across the steel $16 \mathrm{Mo} 3$ - Inconel 625 interface document the presence of a very narrow transition zone (about $50 \mu \mathrm{m}$ ), which is larger in the case of the inner bending arc. The reason is the thinning of the layer in the area of tensile stresses (outer arc bend) and the increase of its thickness in the area of compressive stresses (outer arc bend).

- In general, higher values of nanoindentation hardness were measured in the area of inner bendig arc than in outer inner arc. The reason is again the presence of compressive stresses in this area.

\section{Acknowledgement}

This publication was created in the frame of the project: Advancement and support of $R \& D$ for "Centre for diagnostics and quality testing of materials" in the domains of the RIS3 SK specialization, ITMS2014+:313011W442, based on the Operational Programme Integrated Infrastructure and funded from the European Regional Development Fund. 


\section{References}

[1] KUREK, A., (2020).: Using fatigue characteristics to analyse test results for 16Mo3 Steel under tensioncompression and oscillatory bending conditions. Opole, Pol'sko: Faculty of Mechanical Engineering, Opole University of Technology, pp. 12.

[2] HE, X., CHEN, J., TIAN, W., JIN, W., (2018).: Low Cycle Fatigue Behavior of Steam Generator Tubes under AxialLoading. Materials.

[3] Available on: http://www.techmagazin.cz/2138

[4] Available on: https://www.basedosteel.com/en/materials/material/15415.html

[5] S. Rajendra Prasad, Dr. K.Ravindranath, Dr.M.L.S. Devakumar: Experimental Study and Optimization in Modified Air Abrasive Jet Machining on Nickel-233 Alloy Using MCDM Techniques, Manufacturing Technology, 2019, 19(6):1010-1019

[6] KEJHA, R., (2017).: Výroba, použití a vlastnosti niklových slitin: Bakalárska práca. Brno : VUT, 2017. pp. 42, available on: https://www.vutbr.cz/www_base/zav_prace_ soubor_verejne.php?file_id=149955

[7] Nickel alloys, (2017):: Special Metals \& PCC company. Available on: http://www.specialmetalswiggin.co.uk/products/by-alloy

[8] Nickel \& High Temp Alloys, (2017).: Continental Steel \& Tube Company. Fort Lauderdale, FL, 33303: Continental Steel \& Tube Company, 2017. Available on: http://continentalsteel.com/nickel-alloys/

[9] KASSNER, M.E., et al., (2021): Low Cycle Fatigue Behavior of Steam Generator Tubes under AxialLoading. Materials, pp. 14.

[10] AZO Materials, (2017).: London: AZO Materials, 2017. Available on: http://www.azom.com/

[11] FLOREEN, S., FUCHS, G.E., YANG, W.J., (1994):: The metallurgy of alloy IN625, in: E.A. Loria (Ed.), Superalloys 718, IN625, 706 and Various Derivatives, TMS, Warrendale, pp. 13-37.

[12] HAN, P., (2017).: Additive design and manufacturing of jet engine parts, Engineering 3 (2017), pp. 648-652.

[13] Kusmierczak S., Peslova F., Naprstkova N.: Influence of Heat Treatment Regime on Corrosion Resistance of Clad Aluminium Alloy, $\mathrm{Ma}$ nufacturing Technology 2019, 19(4):624631 | DOI: 10.21062/ujep/345.2019/a/12132489/MT/19/4/624
[14] NEMECEK, S., FIDLER, L., FI_SEROV_A, (2014):: Corrosionresistance of laser clads of Inconel625 and Metco 41C, Phys. Procedia 56(2014) $294 \mathrm{e} 300$ https://doi.org/10.1016/j.phpro.2014.08.174.

[15] ABIOYE, T.E., FARAYIBI, P.K, CLARE, A.T., (2017).: A comparative study of Inconel 625 lasercladding by wire and powderfeedstock, Mater. Manuf. Process. 32 (2017)1653e1659, https://doi.org/10.1080/10426914.2017.1317 787.

[16] SOLECKA, M., KOPIA, A., RADISZEWSKA, A., RUTKOWSKI, B., (2018)::Microstructure, microsegregation and nanohardness of CMT cladlayers of Ni-base alloy on 16Mo3 steel, Journal of Alloys and Compounds, pp. 86 - 95. Vol. 751

[17] ZHANG, Y., LI, Z., NIE, P., WU, Y., (2013).: Carbide and nitrideprecipitationduring lasercladding of Inconel 718 alloycoatings, Optic Laser. Technol. $\quad 52 \quad$ (2013) 30e36,https://doi.org//10.1016/j.optlastec.20 13.03.023.

[18] EN 10028-2, FlatProducts Made of SteelsforPressurePurposes - Part 2: Nonalloyand alloySteelswithSpecifiedElevatedTemperatureProperties, vol. 3,2000.

[19] SpecialMetalsCorporation, Corporationinformationmaterials, http://www.specialmetals.com/assets/smc/documents/alloys/inconel/inconel-alloy-625.

[20] R.M. Sharp, M.C. Flemings, Soluteredistribution in cellularsolidification, Metall. Trans. 5 (1974) pp. 823-830, https://doi.org/10.1007/BF02643134.

[21] DURST, H.V.K, GOKEN, M.,(2004).: Finite element study for nanoindentation measurementson two-phasematerials, J. Mater. Res. 19 (2004)

$85 \mathrm{e} 93$ https://doi.org//10.1557/jmr.2004.19.1.85.

[22] ROZMUS-GÓRNIKOWSKA, M., BLICHARSKI, M., KUSINSKI, J., (2014).: Influence of weldoverlyingmethods on microstructure and chemicalcomposition of Inconel 625 boilerpipecoatings. Metalic Materials, pp. 141-147, Vol. 521.

[23] ZHANG, Y.C., YU, X.T., JIANG, W., TU, S.T., ZHANG, X.C.,(2020).: Elasticmodulus and hardnesscharacteriziationformicroregion of Inconel 625/BNi-2 vacuumbrazedjoint by hightemperature nanoindentation . Vacuum, Vol. 181., Article No.109582 
[24] ARAFIN, M., MEDJAR, M., TURNER, D., BOCHER, P.,(2007).: Transientliquidphasebonding of Inconel 718 and Inconel 625 with BNi-2: modeling and experimentalinvestigations, Mater. Sci. Eng. A 447 (2007) pp. 125-133.

[25] WHEELER, J.M., MICHLER, J.,(2013).: Indentermaterialsforhightemperature nanoindentation, Rev. Sci. Instrum. Vol. 84 (2013) 101301.

[26] ZHANG, Y.C., JIANG, W., TU, S.T., WEN, J.F., WOO,W.,(2014).: Usingshort-timecreeprelaxationeffect to decreasetheresidualstress in thebondedcompliantseal of planarsolid oxide fuelcell-A finite element simulation, $J$. PowerSources, pp. 108-115, Vol. 255.

[27] DONG, H., XIA, Y., XU, X., NAZ, G.J., HAO, X., LI, P., ZHOU, J., DONG,C.,(2020).: Performance of GH4169 brazedjointusing a new designednickel-basedfiller metal viaclusterplus-glue-atom model, J. Mater. Sci. Technol. pp.89-98, Vol. 39. 